\title{
Comparison of the indentation strength and single-edge-v-notched beam methods for dental ceramic fracture toughness testing
}

\author{
Natália Bertolo Domingues', Beatriz Regalado Galvão², Sebastião Ribeiro3 ${ }^{3}$ Antonio Alves de Almeida Junior', \\ Diogo Longhini5, Gelson Luís Adabo ${ }^{5}$ \\ 'Universidade Estadual Paulista - UNESP, Araraquara Dental School, Department of Pediatric Dentistry and Orthodontics, Araraquara, SP, Brazil \\ 2Universidade Potiguar Laureate International Universities - UNP, Dental School, Department of Dental Materials and Prostodonthics, Natal, RN, Brazil \\ ${ }^{3}$ Universidade de São Paulo - USP, Lorena Engineering School, Department of Engineering Materials, Lorena, SP, Brazil \\ ¿Universidade Tiradentes - UNIT, Dental School, Department of Dental Materials and Prostodonthics, Aracaju, SE, Brazil \\ ${ }^{5}$ Universidade Estadual Paulista - UNESP, Araraquara Dental School, Department of Dental Materials and Prostodonthics, Araraquara, SP, Brazil
}

Received for publication: July 06, 2016 Accepted: August 25, 2016

Correspondence to: Gelson Luís Adabo

Faculdade de Odontologia de Araraquara - UNESP CEP: 14801-903 Rua Humaitá, 1680 Araraquara, SP, Brasil Phone: $+55163301-6415$ E-mail: adabo@foar.unesp.br

\begin{abstract}
Aim: To study influence of the cooling rate after sintering a veneering porcelain (Vita VM9) on fracture toughness by indentation strength (IS) and single-edge-v-notched beam (SEVNB) methods. Methods: Vita VM9 bars were sintered according to the manufacturer's recommendation and cooled under three conditions: Slow (inside the furnace from sintering temperature to room temperature); Normal (inside the furnace from sintering temperature to $500{ }^{\circ} \mathrm{C}$ and outside the furnace from $500{ }^{\circ} \mathrm{C}$ to room temperature); and Fast (outside the furnace from sintering temperature to room temperature). Fracture toughness was measured by IS $(n=10)$ and SEVNB $(n=10)$ methods. Data were analyzed by two-way ANOVA ( $a=0.05)$. Results: The fracture toughness obtained from SEVNB (slow - 1.02 \pm 0.10 ; normal - $1.09 \pm 0.13$; and fast $-1,02 \pm 0.18 \mathrm{MPa} . \mathrm{m}^{1 / 2}$ cooling techniques) was significantly lower than IS (slow $-1.19 \pm 0.13$; normal $-1.17 \pm 0.07$; and fast $-1.16 \pm 0.06 \mathrm{MPa}$. $\mathrm{m}^{1 / 2}$ cooling techniques). There was no significant influence of the cooling technique $(\mathrm{p}=0.012)$. Conclusions: The measurement technique influenced the fracture toughness values. IS method overestimated the fracture toughness values. Irrespective of the measuring method, cooling rate did not influence the Vita VM9 veneering porcelain fracture toughness.
\end{abstract}

Keywords: Ceramics. Mechanical Processes. Dental Materials.

\section{Introduction}

Yttrium-stabilized tetragonal zirconia polycrystals (Y-TZP) for dental prosthesis became more popular because of its high mechanical performance, but it usually demands veneering with feldsphatic porcelain to improve esthetics. However, chipping the veneering porcelain in Y-TZP prosthesis is more prevalent than for porcelain fused to metal ${ }^{1-5}$. A possible cause of porcelain chipping in Y-TZP restorations is the difference between thermal properties of Y-TZP and porcelain. Y-TZP thermal conductivity and diffusivity is lower than those of porcelain veneer, and temperature gradient may interfere in residual stress development ${ }^{3}$, which depends directly on the cooling rate. It is likely that slow cooling can partially release the residual stresses, but it may reduce the beneficial compressive stress on porcelain surface ${ }^{4}$. On the other hand, a fast cooling rate does not allow for the residual stress relaxation; conversely, it reinforces porcelain on surface by compressive tempering stress. The effects of 
different cooling rates have been studied by computer simulations and mechanical tests, such as flexural strength and fracture toughness. In addition to residual stresses developed because of the different ceramic association, there is a possible effect of cooling rate on the mechanical properties of porcelain, in spite of its attachment to the substructure ${ }^{6,7}$.

Fracture toughness, defined as the resistance to fast crack propagation at a critical stress level (KIC), is widely used for mechanical characterization of dental ceramics ${ }^{8-10}$. Several techniques for measuring fracture toughness of ceramics have been described, such as single-edge-v-notched beam (SEVNB), indentation strength (IS) and indentation fracture (IF). These techniques differ by two different modalities, notch and indentation ${ }^{9,11-13}$.

The SEVNB, is considered the most reliable, accurate and reproducible method ${ }^{12,14}$. It is the test advised by ISO $6872: 2008^{15}$, which specifies the requirements and the test methods for dental ceramic materials. However, this technique demands caution to be performed, because it requires the preparation of large bar shaped specimens (4 mm x $3 \mathrm{~mm}$ × $22 \mathrm{~mm}$ ), straight-through notch, precise notch length measurement, and determination of the critical crack tip radius ${ }^{9,12}$. Moreover, the ceramic microstructure may affect the notch preparation, and the result may be underestimated due to the pre-cracks ${ }^{16,17}$.

Alternatively, the IS method is simple, economical and requires fewer specimens ${ }^{14,18}$. To calculate the fracture toughness, it is necessary to know the material's elastic modulus and to measure Vickers hardness in a small sample ${ }^{18,19}$. Nevertheless, for running this method, special care is required. Specimens should have a flat and polished surface with no crack chipping or branching. It is important to highlight that problems with high rejection rate of Vickers indentations may affect the reliability of fracture toughness data, due to route deviations in cracks and chipping around the indent, errors in length measurements of crack and progressive slow crack growth ${ }^{9}$. Although it does not provide exact fracture toughness values, there is some agreement with other mechanical tests for dental materials ${ }^{9}$. Because of these characteristics, some authors named this method as Apparent Fracture Toughness.

The SEVNB method is recommended by the ISO 6872:2008 ${ }^{15}$, but presents some disadvantages regarding specimen size and difficulty to prepare, while the IS method is easier and faster to perform, the purpose of this study was to compare fracture toughness of a veneering porcelain subjected to different cooling rates measured by IS and SEVNB methods.

\section{Material and methods}

Monolayer bar shaped specimens of Vita VM9 (Vita Zahnfabrik, Bad Säckingen, Baden-Württemberg, Germany) feldspathic porcelain were prepared by mixing the powder and liquid (VITA Modeling Liquid, Vita Zahnfabrik,). The slurry was inserted into a polyether mold (Impregum F, 3M ESPE, Seefeld, Baviera, Germany) of $4.5 \mathrm{~mm}$ x $5.5 \mathrm{~mm}$ x $25 \mathrm{~mm}$ for SEVNB or $2.4 \mathrm{~mm} \times 6 \mathrm{~mm} \times 14.5 \mathrm{~mm}$ for IS, 20\% larger than the expected final dimensions because of the sintering shrinkage. The excess liquid was blotted with absorbent paper before the specimen's removal from the mold. The specimens were sintered in an oven (EDG, São Carlos, SP, Brazil) according to the manufacturer's instructions and cooled at three different rates: fast, slow and regular (Table 1).

Table 1 - Cooling methods applied on the specimens, according to the group.

\begin{tabular}{lcc}
\hline GROUPS & METHOD OF COOLING & $\begin{array}{c}\text { APPROXIMATE TIME } \\
\text { TO THE COOLING }\end{array}$ \\
Slow & $\begin{array}{c}\text { Samples were left inside the } \\
\text { closed, turned-off furnace until they } \\
\text { reached room temperature. } \\
\text { The elevator of the furnace was } \\
\text { lowered, and when } \\
\text { Normal } \\
\text { the temperature inside the furnace } \\
\text { reached } 500^{\circ} \mathrm{C} \text {, the samples } \\
\text { were removed and cooled at room } \\
\text { temperature. }\end{array}$ & \\
& $20 \mathrm{~min}$ \\
Fast & $\begin{array}{c}\text { Samples were removed from } \\
\text { the furnace immediately after } \\
\text { the holding time and blasted by } \\
\text { compressed air. }\end{array}$ \\
\hline
\end{tabular}

\section{Fracture toughness by SEVNB}

After cooling, the specimens $(n=10)$ were bonded on a metal plate and rectified by a grinding machine (Rectifier flat tangential model TA42; FERDIMAT, São Paulo, SP, Brazil) until reaching the final dimensions of $4 \pm 0.25 \mathrm{~mm}$ width, 1.2 $0.2 \mathrm{~mm}$ thickness and $22 \mathrm{~mm}$ length. A cut was made across the surface of the specimens, with a diamond cutting disc $(0.3$ mm thick), perpendicular to the length of the bars, as a starter notch $0.5 \mathrm{~mm}$ deep. The produced notches were filled with diamond polishing pastes $(3 \mu \mathrm{m})$ and it were finished using a razor blade attached to a custom machine with an uniform backand-forth movements to achieve a controlled and smooth notch. The notches were examined in an optical microscope (M80; Leica Microsystems Ltd., Heerbrugg, St. Gallen, Switzerland) to check the depth, which ranged from $0.8 \mathrm{~mm}$ to $1.2 \mathrm{~mm}$. The specimens were cleaned with acetone in an ultrasonic bath ${ }^{15}$.

The specimens were placed with the $\mathrm{V}$-shaped notch down and loaded at the speed of $0.5 \mathrm{~mm} / \mathrm{min}$, at room temperature, in a universal testing machine (MTS 810 - Material Test System, Eden Prairie, MN, USA). The thickness (b), and width (w) of each specimen were measured with a caliper. The depths of the $\mathrm{V}$-shaped notches were measured in three positions (a1, a2, a3) using a stereomicroscope (M80, Leica) at 50x magnification. To accept each test, an optical microscope (M80, Leica Microsystems) verified if the fracture started at the bottom of the $\mathrm{V}$-shaped notch and continued for the entire extent. The fracture toughness, $\mathrm{K}_{\mathrm{IC}}$, was calculated by the following equations: 


$$
\begin{gathered}
\mathrm{K}_{\mathrm{IC}}=\frac{\mathrm{P}}{\mathrm{b} \sqrt{w}} \times \frac{\mathrm{S}_{1}-\mathrm{S}_{2}}{w} \times \frac{3 \sqrt{\alpha}}{2(1-\alpha)^{1,5}} Y \\
Y=1.9887-1.326 \alpha-\frac{\left(3.49-0.68 \alpha+1.35 \alpha^{2}\right) \alpha(1-\alpha)}{(1+\alpha)^{2}}
\end{gathered}
$$

Where:

$\mathrm{K}_{\mathrm{IC}}=$ SEVNB fracture toughness $\left(\mathrm{MPa} \cdot \mathrm{m}^{1 / 2}\right)$.

$\sigma=$ fracture strength $(\mathrm{MPa})$

$\mathrm{P}=$ fracture load $(\mathrm{MN})$

$\mathrm{b}=$ Specimen thickness $(\mathrm{mm})$

$\mathrm{w}=$ Specimen width $(\mathrm{mm})$

$\mathrm{S} 1-\mathrm{S} 2$ = difference between the span's upper and lower support (mm)

$\mathrm{Y}=$ form factor of stress intensity

\section{Fracture Toughness by Indentation Strength (IS)}

For Indentation Strength (IS) test, the bars (12 mm x $5 \mathrm{~mm}$ x $2 \mathrm{~mm}$ ) were embedded along their axis in acrylic resin (Jet Artigos Odontológicos Clássico Ltda., São Paulo, SP, Brazil), and ground by 120- to 1500 -grit wet $\mathrm{SiC}$ paper discs for $3 \mathrm{~min}$ each at $400 \mathrm{rpm}$ speed. The polish was made by monocrystalline diamond suspension in an aqueous base, particle size of $3 \mu \mathrm{m}$ (MetaDi; Buehler, Lake Bluff, IL, USA) with polishing cloth (Microcloth; Buehler) for $10 \mathrm{~min}$. The specimens were cleaned by ultrasound in distilled water for $12 \min (n=10)$.

Vickers hardness was measured in the Buehler model 16006300 (Buehler) hardness tester with a $9.8 \mathrm{~N}$ load for $20 \mathrm{~s}$ on a $5 \mathrm{~mm} \times 2 \mathrm{~mm}$ cross-sectional area. Cracks resulting from the Vickers indentation were measured immediately to avoid slow crack growth after printing, started by the stress field that acts upon loading. The images of the cracks were made with a digital video camera model TK-C1380U (JVC, Tokyo, Honshu, Japan) coupled to the hardness tester. The crack extent was measured with an image analysis software (Leica Application Suite EZ; Leica Microsystems Ltd).

The fracture toughness (KIc) was calculated by the following equation:

$$
\mathrm{K}_{\mathrm{IC}}=0.016\left(\frac{\mathrm{E}}{\mathrm{H}}\right)^{\frac{1}{2}} \times\left(\frac{\mathrm{P}}{\mathrm{C}}\right)^{\frac{3}{2}}
$$

Where:

$\mathrm{K}_{\mathrm{IC}}$ : IS fracture toughness (MPa.m $\left.{ }^{1 / 2}\right)$

$\mathrm{E}=$ Modulus of elasticity of the tested material (GPa)

$\mathrm{P}=$ Force at applied for the hardness test $(\mathrm{N})$

$\mathrm{H}=$ Vickers hardness $(\mathrm{GPa})$

$\mathrm{C}=$ Largest lateral extension of the crack $(\mathrm{m})$

\section{Statistics}

Statistical analyzes were performed using two-way ANOVA and Tukey's post hoc test $(\alpha<0.05)$.

\section{Results}

The IS method showed significantly higher values of fracture toughness compared to the SEVNB method $(p=0.012)$. However, two-way ANOVA was not significant for cooling rate $(p=0.144)$ and interactions between cooling rate and fracture toughness method $(\mathrm{p}=0.091)($ Table 2$)$.

Table 2 - Comparison of IS and SEVNB methods according to the cooling protocol (mean $\pm \mathrm{SD}$ ).

\begin{tabular}{lccc}
\hline & \multicolumn{3}{c}{ Cooling Protocol } \\
\cline { 2 - 4 } Method & Slow & Normal & Fast \\
\hline IS & $1.19 \pm 0.13^{\mathrm{aA}}$ & $1.17 \pm 0.07^{\mathrm{aA}}$ & $1.16 \pm 0.06^{\mathrm{aA}}$ \\
SEVNB & $1.02 \pm 0.13^{\mathrm{aB}}$ & $1.09 \pm 0.09^{\mathrm{aB}}$ & $1.01 \pm 0.32^{\mathrm{aB}}$ \\
\hline
\end{tabular}

Different uppercase letters indicate significant differences in columns $(p<0.05)$ - Different lowercase letters indicate significant differences in rows $(p<0.05)$.

\section{Discussion}

Fracture toughness is a useful property to assess the reliability of a material subjected to stresses of mechanical nature ${ }^{20}$. The value of fracture toughness can be affected by factors such as the type of tested dental materials and chosen technique ${ }^{9,21}$. The IS and SEVNB methods were chosen to compare the fracture toughness of dental ceramics because they are the most widely used in the literature. In this study, it was found that there was difference between SEVNB and IS, but cooling rate was not significant irrespective of the measurement method.

SEVNB method is considered the "golden standard" to determine fracture toughness values in ceramics ${ }^{12,15}$. Our SEVNB data are in agreement with other studies ${ }^{9,13,21}$, indicating that this method may reflect the actual material properties due to precise and controlled fracture induced by the $\mathrm{V}$-notch in the specimens ${ }^{22}$. The SEVNB method has been considered as more reliable and accurate, because it provides reproducible toughness values ${ }^{14}$. On the other hand, the SEVNB method is quite sensitive, especially because it requires meticulous notch preparation ${ }^{9}$. If the critical notch length is underestimated; the toughness will be lower than the actual fracture toughness ${ }^{9,14}$ and if the notch root radius is larger, it may produce overestimated results ${ }^{12}$.

With regard to IS technique, overestimated fracture toughness values were found. Chai and $\mathrm{Lawn}^{23}$ suggested that IS method could be a simple and fast way to evaluate the fracture toughness of glassy materials, as few specimens are required for the test ${ }^{9}$. However, according to Fisher and Marx ${ }^{14}$, this technique is not an appropriate tool to determine exactly the fracture toughness of an unknown ceramic material, because the term $\mathrm{E}=0.018$ is a constant value in the equation, but it should not be, since it depends on specific characteristics of each tested ceramic material. In 
addition, Scherrer et al. ${ }^{9}$ pointed out that there is greater dispersion of data by IS method, for being a superficial measure that may be influenced by residual stresses on the surface. Moreover, if the indenter produces chipping, the measurement of hardness mark and resulting cracks may produce inaccurate parameters to introduce in the equation. Actually, it is difficult to measure precisely the crack length ${ }^{24}$ and the crack measurement may vary because of slow crack growth ${ }^{9}$. Conversely, our results exhibited low standard deviation. This may be due to the close finishing protocol that allowed clear visualization of the mark and cracks, as well as the time standardization for measuring the cracks. Regardless of this, IS is an affordable alternative method ${ }^{14}$ and it should be used only when the standard SEVNB method cannot be performed, such as for specimens obtained from small dental ceramic blocks.

Additionally, the manufacturers recommended slow cooling to reduce clinical failure rates and there is no standardization in the different cooling methods ${ }^{25}$. The ideal cooling protocol is not yet established. The effect of thermal properties of zirconia and feldspathic porcelain on veneer chipping has been addressed extensively in recent years, but the possible effect solely on the porcelain was not studied, in spite of being applied on zirconia. In theory, cooling rate may potentially induce phase transformation in leucite, and it may interfere on the mechanical properties ${ }^{2,6,7,26,27}$. However, in the present study, different methods of cooling did not differ from each other and there was no interaction with the fracture toughness techniques.

In summary, cooling rates did not influence fracture toughness of the studied porcelain, irrespective of the measurement method, but the IS method overestimates the fracture toughness values.

\section{Acknowledgements}

The authors acknowledge the support of the Sao Paulo Research Foundation (FAPESP) Grants 2010/05469-9 and 2010/05395-5.

\section{References}

1. Sailer I, Feher A, Filser F, Gauckler LJ, Luthy H, Hammerle CH. Five year clinical results of zirconia frameworks for posterior fixed partial dentures. Int J Prosthodont. 2007 Jul-Aug;20(4):383-8.

2. Choi JE, Waddell JN, Swain MV. Pressed ceramics onto zirconia. Part 2: indentation fracture and influence of cooling rate on residual stresses. Dent Mater. 2011 Nov;27(11):1111-8. doi: 10.1016/j.dental.2011.08.003.

3. Swain MV. Unstable cracking (chipping) of veneering porcelain on allceramic dental crowns and fixed partial dentures. Acta Biomater. 2009 Jun;5(5):1668-77. doi: 10.1016/j.actbio.2008.12.016.

4. Göstemeyer G, Jendras M, Dittmer MP, Bach F, Stiesch M, Kohorst P. Influence of cooling rate on zirconia/veneer interfacial adhesion. Acta Biomater. 2010 Dec;6(12):4532-8. doi: 10.1016/j.actbio.2010.06.026.

5. Pjetursson BE, Sailer I, Makarov NA, Zwahlen M, Thoma DS. All-ceramic or metal-ceramic tooth-supported fixed dental prostheses (FDPs)? A systematic review of the survival and complication rates. Part II: Multiple-unit FDPs. Dent Mater. 2015 Jun;31(6):624-39. doi: 10.1016/j. dental.2015.02.013.

6. Mackert JR, Jr., Evans AL. Effect of cooling rate on leucite volume fraction in dental porcelains. J Dent Res. 1991 Feb;70(2):137-9.

7. Mackert JR, Jr., Twiggs SW, Russell CM, Williams AL. Evidence of a critical leucite particle size for microcracking in dental porcelains. J Dent Res. 2001 Jun;80(6):1574-9.

8. Mecholsky JJ Jr. Fracture mechanics principles. Dent Mater. 1995 Mar;11(2):111-2.

9. Scherrer SS, Denry IL, Wiskott HW. Comparison of three fracture toughness testing techniques using a dental glass and a dental ceramic. Dent Mater. 1998 Jul;14(4):246-55.

10. Wang RR, Lu CL, Wang G, Zhang DS. Influence of cyclic loading on the fracture toughness and load bearing capacities of all-ceramic crowns. Int J Oral Sci. 2014 Jun;6(2):99-104. doi: 10.1038/ijos.2013.94.

11. Wang $H$, Pallav $P$, Isgro $G$, Feilzer AJ. Fracture toughness comparison of three test methods with four dental porcelains. Dent Mater. 2007 Jul;23(7):905-10.

12. Fischer $H$, Waindich $A$, Telle $R$. Influence of preparation of ceramic SEVNB specimens on fracture toughness testing results. Dent Mater. 2008 May;24(5):618-22.

13. Triwatana $P$, Srinuan $P$, Suputtamongkol K. Comparison of two fracture toughness testing methods using a glass-infiltrated and a zirconia dental ceramic. J Adv Prosthodont. 2013 Feb;5(1):36-43. doi: 10.4047/ jap.2013.5.1.36.

14. Fischer $\mathrm{H}$, Marx R. Fracture toughness of dental ceramics: comparison of bending and indentation method. Dent Mater. 2002 Jan;18(1):12-9.

15. International Organization for Standardization. ISO 6872: 2008: Dental ceramics, Switzerland; 2008

16. Hermann R, Moffatt J, Plumbridge WJ. A comparison of crack initiation techniques for ceramics. J Mater Sci Lett. 1995;14:282-4.

17. Quinn JB, Sundar V, Lloyd IK. Influence of microstructure and chemistry on the fracture toughness of dental ceramics. Dent Mater. 2003 Nov;19(7):603-11.

18. Anstis GR, Chantikul P, Lawn BR, Marshall BD. A critical evaluation of indentation techniques for measuring fracture toughness: I, Direct crack measurement. J Am Ceram Soc. 1981;64(9):533-8.

19. Evans $A G$, Charles EA. Fracture toughness determinations by indentation. J Am Ceram Soc. 1976;59:371-2.

20. Pecnik CM, Courty D, Muff D, Spolenak R. Fracture toughness of esthetic dental coating systems by nanoindentation and FIB sectional analysis. J Mech Behav Biomed Mater. 2015 Jul;47:1-11. doi: 10.1016/j. jmbbm.2015.03.006.

21. Coldea A, Swain MV, Thiel N. In-vitro strength degradation of dental ceramics and novel PICN material by sharp indentation. J Mech Behav Biomed Mater. 2013 Oct;26:34-42. doi: 10.1016/j.jmbbm.2013.05.004.

22. Strecker K, Ribeiro S, Hoffmann MJ. Fracture toughness measurements of LPS-SiC: A comparison of the indentation technique and the SEVNB method. Mater Res. 2005 Feb;8(2):121-4.

23. Chai $H$, Lawn BR. A universal relation for edge chipping from sharp contacts in brittle materials: A simple means of toughness evaluation. Acta Mater. 2007 Apr;55:2555-61.

24. Guazzato M, Albakry M, Swain MV, Ironside J. Mechanical properties of In-Ceram Alumina and In-Ceram Zirconia. Int J Prosthodont. 2002 Jul-Aug;15(4):339-46.

25. Almeida AA Jr, Longhini D, Domingues NB, Santos C, Adabo GL. Effects of extreme cooling methods on mechanical properties and shear bond strength of bilayered porcelain/3Y-TZP specimens. J Dent. 2013 Apr;41(4):356-62. doi: 10.1016/j.jdent.2013.01.005.

26. Cesar PF, Yoshimura HN, Miranda Junior WG, Okada CY. Correlation between fracture toughness and leucite content in dental porcelains. J Dent 2005 Oct;33(9):721-9.

27. Ong JL, Farley DW, Norling BK. Quantification of leucite concentration using X-ray diffraction. Dent Mater. 2000 Jan;16(1):20-5. 